\title{
Strategies of Treatment for Extensively Drug-Resistant Acinetobacter baumannii Infections: Single Centre Experience
}

Islas-Muñoz Beda Daniela1 ${ }^{1}$, Villegas-Acosta Liudmila ${ }^{1}$, Aguilar-Zapata Daniel ${ }^{1}$, Váldez-Vázquez Rafael ${ }^{1}$, López-Escamilla Eduardo ${ }^{1}$, Rodríguez-Badillo Raymundo $^{2}$ and Ana Patricia Rodriguez Zulueta ${ }^{1^{*}}$

${ }^{1}$ Department of Infectious Diseases, Clinical Laboratory, Hospital General Doctor Manuel Gea Gonzalez Infectious Disease, Mexico

${ }^{2}$ Intensive Care Unit, Hospital General Doctor Manuel Gea Gonzalez Infectious Disease, Mexico

"Corresponding author: Rodriguez Zulueta AP, Department of Infectious Diseases, Clinical Laboratory, Hospital General Doctor Manuel Gea Gonzalez Infectious Disease, Clazada de Tlalpan 4800, Mexico, Tel: 525532220304; E-mail: rozu76@hotmail.com

Received date: May 22, 2017; Accepted date: June 10, 2017; Published date: June 17, 2017

Copyright: () 2017 Islas-Muñoz, et al. This is an open-access article distributed under the terms of the Creative Commons Attribution License; which permits unrestricted use; distribution; and reproduction in any medium; provided the original author and source are credited.

\begin{abstract}
Objective: To describe treatment strategies employed in hospitalized patients at the "General Hospital Dr. Manuel Gea González" with infection by Extensively Drug-Resistant (XDR) Acinetobacter baumannii.

Methodology: A retrospective analysis was carried out from January 1st 2012 to December 31st, 2014. Clinical data were collected, as well as group and doses of antimicrobial agents administered.

Results: 39 patients were enrolled, the main infectious diagnosis was hospital acquired pneumonia (HAP) in $64 \%$, followed by skin and soft-tissue infections (SSTI) in $23 \%$. Thirty patients (77\%) received tigecycline, while $83 \%$ of these received high doses. Thirty three percent of patients receiving meropenem had high dose. Twenty-nine patients $(74.3 \%)$ received colistin and, from these, $61.5 \%$ was given a loading dose. Concerning the combined therapy, the following distribution was observed: 19 patients $(48.7 \%)$ had triple therapy: meropenem, colistin and tigecycline (MCT), and 20 patients $(51.3 \%)$ had double therapy including combinations of meropenem-colistin (MC), meropenem-tigecycline (MT) and tigecycline-colistin (TC). The sole adverse effect with the use of tigecycline was nausea in $20 \%$. Twenty five percent of patients receiving colistin required dose adjustment after 5 days due to acute kidney injury $(\mathrm{AKI})$. Outcomes: overall mortality was 33.3\%, the mean of hospital stay at the intensive care unit (ICU) was 12.8 days (SD \pm 16.2 ), while the total days of stay were 41 (SD \pm 25.9$)$. The lowest mortality (25.3\%) was observed in the group receiving triple therapy (MCT), although this was no statistically significant.
\end{abstract}

Conclusions: Triple combination therapy showed a trend to decreased mortality. The use of tigecycline at high doses and colistin at loading dose did not determine unfavorable clinical outcomes. It is necessary to perform randomized studies comparing different therapeutic strategies.

Keywords: XDR-Acinetobacter baumannii; Combined therapy; Colistin multidrug resistant infections

\section{Introduction}

Acinetobacter baumannii is a microorganism of great clinical relevance, is considered one of the most frequent nosocomial pathogens in recent years. Although is considered a low virulent microorganism, the treatment has been a challenge due to the high resistance rates that exhibits towards the available antimicrobial agents $[1,2]$. It can be isolated from the skin, oral cavity, and gastrointestinal tract in healthy hosts.

The presences of this microorganism have been documented in medical equipment within hospitals, such as humidifiers, ventilators, mattresses and other surfaces. There are at least 21 strains, in the clinical practice, the genospecies 1 (A. colcoaceticus), 2 ( $A$. baumannii), and 13 (A. baumannii-colcoaceticus) represent about $80 \%$ of the pathogens resulting in nosocomial infections $[1,3]$.

Infection foci that have been reported are the lung, urinary tract, blood, central nervous system, and peritoneum. The rate of bacteremia reported at the ICU (intensive care unit) is $1.6 \%$ and it is usually documented following long-term stays, with a mean value of 26 days [2]. The overall mortality rate in patients with bacteremia by XDR $A$. baumannii at the ICU has been reported of $43 \%$.

The mortality attributable to the infection is variable and difficult to determine because patients usually have other comorbidities; a critical condition, long-term hospital stay and multiple organ system failure; these may influence poor outcomes $[4,5]$.

The objective of the treatment is to achieve clinical cure with a subsequent decrease in mortality. Early start of appropriate antimicrobial therapy have been demonstrated a significant reduction in mortality [6].

Optimal antimicrobial treatment is a challenge due to the high resistance of the microorganism and the difficulty to determine the in vitro susceptibility for some antimicrobials such as colistin and tigecycline [2].

Tigecycline is a broad-spectrum antimicrobial agent with in vitro activity against Gram-positive, gram-negative and multidrug-resistant (MDR) pathogens. Only Pseudomonas aeruginosa and species of the genus Protea exhibit in vitro resistance. Said it is approved to treat complicated intra-abdominal infections and skin and soft tissue 
infections (SSTI). Up to $78 \%$ of circulating strains of XDR $A$. baumannii have in vitro susceptibility to tigecycline [2-7] .

It has been postulated that tigecycline cannot reach it pharmacodynamics objective using standard doses in clinical samples with a minimal inhibitory concentration (MIC) between $1-2 \mathrm{mcg} / \mathrm{mL}$ [8]. Two systematic reviews reported that high dose (HD) of tigecycline had significantly less ICU mortality and better clinical outcomes than standard doses $[9,10]$. Other studies reported higher rates of clinical resolution and microbiological eradication using HD of tigecycline strategy in patients with ventilator associated pneumonia (VAP) $[11,12]$. Other studies could not demonstrate clinical efficacy with the use of tigecycline,in fact, they showed lower microbiological eradication and high mortality rates (up to $41 \%$ ) $[13,14]$.

Colistin is another option of treatment for $A$. baumannii infections. Colistin (polymyxin $E$ ) has been available since 1960 and was replaced in 1970 due to its nephrotoxicity and neurotoxicity. There are several clinical studies about colistin effectiveness to treat complicated infections by XDR microorganisms ( $A$. baumannii, $P$. aeruginosa, $K$. pneumoniae). Strategies to improve the bioavailability of colistin are related to a loading dose (LD) and the administration of prolonged infusions $[15,16]$.

Drugs that have typically shown susceptibility to XDR A. baumannii are colistin, rifampicin, and tetracyclines. In the presence of MDR Acinetobacter baumannii, Pseudomonas aeruginosa and Klebsiella pneumoniae colistin have shown synergic effect in combination with other antimicrobials such as carbapenems, rifampicin, tigecycline, amynoglycosides, fosfomycin and levofloxacin $[2,3]$.

The highest synergy rate reported recently is $67.4 \%$ (95\% CI, 27.3-91.9) for tigecycline in combination with colistin [17]. In Turkey, Timurkaynak et al. [18] analyzed 25 strains of MDR A. baumannii and tested 5 of them for synergy with combinations of antibiotics. The combination of colistin with rifampicin showed synergy in $100 \%$ of strains.

In 2016 Gram negative bacteria resistant to colisitin have emerged as an important public health issue. Although for resistant enterobacteria new antimicrobial are available, Acinetobacter have no different options. A promising strategy for treating XDR A. baumannii infections is the triple antimicrobial combination [19].

\section{Objective}

To describe treatment strategies for patients hospitalized at the General Hospital Dr. Manuel Gea González in Mexico City, Mexico, with infection by XDR A. baumannii, including: High-doses (HD) of tigecycline, loading-dose (LD) of colistin, and combined therapy.

\section{Methodology}

A retrospective analysis was carried out in patients hospitalized with infections by XDR A. baumannii from January 1st 2012 to December 31st, 2014. Clinical data were collected, as well as group of antibiotics, doses and time of administration. XDR was defined as resistance to all the groups of active antibiotics with exception of 2 or less categories. Acute kidney Injury (AKI) was defined as an increase of creatinine twice its baseline value 72 hours after the beginning of the antimicrobial.

To determine severity of disease we used Quick Secuential Organ Failure Assessment (q-SOFA) score. It uses three criteria, assigning one point for high respiratory rate ( $\geq 22$ breaths/min), low systolic blood pressure $(\leq 100 \mathrm{mmHg})$, and altered mental status. This score predicts mortality for patients with suspected sepsis [20-27].

Doses of antibiotics were defined as follows: standard dose (SD) tigecycline: $\mathrm{LD}$ of $100 \mathrm{mg}$ followed by $50 \mathrm{mg}$ bid (twice a day); HD tigecycline: LD of $200 \mathrm{mg}$ followed by $100 \mathrm{mg}$ bid; HD meropenem: 2 gms for every 8 hours and LD colistin: $5 \mathrm{mg}$ per kilogram with a maximum dose of $300 \mathrm{mg}$. Subsequent doses of colistin were $150 \mathrm{mg}$ twice a day.

Combined therapy was classified as triple therapy if the patient received together meropenem, colistin and tigecycline (MCT) and double therapy if the patient received any of the following combinations: meropenem-colisitn (MC), meropenem-tigecycline (MT) or colistin-tigecyclinie (CT). Clinical parameters were collected at the beginning of antimicrobials and after 72 hours.

Strains were analyzed in the automatic equipment Microscan ${ }^{\circ}$ (Beckman Coulter) during the year of 2013. In 2014 the automatic system VITEK $2^{\circ}$ (bioMérieux) was introduced and included susceptibility tests to colistin and tigecycline.

Infectious syndromes Hospital acquired pneumonia (HAP), SSTI, abdominal sepsis, osteomyelitis, otitis media, urosepsis, and peritonitis) were defined according to the 2005 CDC (Centers for Disease Control and Prevention) criteria for disease definition [20].

\section{Results}

Thirty nine patients were enrolled in the study, $70 \%$ were male with a mean of age of 49.4 years old (SD \pm 17.5$)$. The major comorbidities were diabetes mellitus (43.5\%), hemiplegia (25.6\%), chronic kidney disease $(25.6 \%)$ and obesity (12.8\%) (Table 1$)$.

\begin{tabular}{|l|l|}
\hline Variable & Mean \pm SD/ Total (\%) \\
\hline Men & $27(70)$ \\
\hline Age & $49.4(\mathrm{DE} \pm 17.5)$ \\
\hline Diabetes mellitus & $17(43.5)$ \\
\hline CKD & $10(25.6)$ \\
\hline Hemiplegia & $10(25.6)$ \\
\hline Morbid obesity & $5(12.8)$ \\
\hline Steroids use & $4(10.2)$ \\
\hline Immunosupresant drugs & $3(7.6)$ \\
\hline $\begin{array}{l}{ }^{*} \text { Methotrexate (predominantly) } \\
\text { CKD: Chronic kidney disease; CHF: Chronic heart failure; COPD: Chronic } \\
\text { obstructive pulmonary disease; } \\
\text { standard deviation }\end{array}$ & \multicolumn{2}{|l}{ Human Immunodeficiency Virus; SD: } \\
\hline
\end{tabular}

Table 1: Baseline characteristics of the studied patients.

The most common hospital admitting diagnoses were SSTI (30.7\%), multiple contusions (15.3\%) and urosepsis (10.2\%) (Table 2).

The most common isolation site of $A$. baumannii were bronchial sample, related to HAP in $64 \%$, followed by skin swab, related to SSTI in $23 \%$ (Table 3 ). 
Citation: Islas-Muñoz, Liudmila VA, Daniel AZ, Rafael VV, Eduardo LE, et al. (2017) Strategies of Treatment for Extensively Drug-Resistant Acinetobacter baumannii Infections: Single Centre Experience. J Infect Dis Med 2: 106. doi:10.4172/2576-1420.1000106

Page 3 of 6

\begin{tabular}{|l|l|}
\hline Variable & Mean \pm SD/ Total (\%) \\
\hline SSTI & $12(30.7)$ \\
\hline Stroke & $4(10.2)$ \\
\hline Urosepsis & $4(10.2)$ \\
\hline Multiple contusions & $6(15)$ \\
\hline CAP & $3(7.6)$ \\
\hline Abdominal surgery & $2(5.1)$ \\
\hline Abdominal sepsis & $1(2.5)$ \\
\hline Osteomyelitis & $1(2.5)$ \\
\hline CSOM & $1(2.5)$ \\
\hline Tuberculosis & $1(2.5)$ \\
\hline Mucormycosis & $1(2.5)$ \\
\hline Influenza & $1(2.5)$ \\
\hline SBP & $1(2.5)$ \\
\hline Empiema & $1(2.5)$ \\
\hline
\end{tabular}

\begin{tabular}{|l|l|}
\hline Total patients with tigecycline & $30(77)$ \\
\hline HD tigecycline & $25(83)$ \\
\hline SD tigecycline & $5(17)$ \\
\hline Total patients with meropenem & $35(90)$ \\
\hline HD meropenem & $12(34)$ \\
\hline Total patients with colistin & $29(74)$ \\
\hline LD colistin & $24(82)$ \\
\hline Triple therapy & $18(46)$ \\
\hline Double therapy MC & $9(23)$ \\
\hline Double therapy MT & $8(21)$ \\
\hline Double therapy CT & $4(10)$ \\
\hline $\begin{array}{l}\text { HD: high doses; SD: standard doses; LD: loading doses; MC: meropenem- } \\
\text { colistin; MT: meropenem-tigecycline; CT: colistin-tigecycline *SD standard } \\
\text { deviation }\end{array}$ & \\
\hline
\end{tabular}

SSTI: Skin and soft tissue infections; CAP: Community acquired pneumonia; CSOM: Chronic suppurative otitis media; SBP: Spontaneous bacterial peritonitis. SD: Standard deviation

Table 2: Diagnosis at hospital admission.

\begin{tabular}{|l|l|}
\hline Variable & Mean \pm SD/ Total (\%) \\
\hline HAP & $25(64)$ \\
\hline SSTI & $9(23)$ \\
\hline Abdominal sepsis & $2(5.1)$ \\
\hline Osteomyelitis & $1(2.5)$ \\
\hline CSOM & $1(2.5)$ \\
\hline UTI & $1(2.5)$ \\
\hline $\begin{array}{l}\text { HAP: Hospital acquired pneumonia; SSTI: Skin and soft tissue infections; } \\
\text { CSOM: Chronic suppurative otitis media; UTI: Urinary tract infections. SD: } \\
\text { Standard deviation }\end{array}$ \\
\hline
\end{tabular}

Table 3: Infectious diagnosis with isolation of XDR A. baumannii. For HAP the samples collected were bronchial aspiration; for skin and soft tissue infections predominantly were swabs; in abdominal sepsis were peritoneal fluid or drainage from intra-abdominal collections; for osteomyelitis bone sample were collected.

The various therapeutic strategies are shown in (Table 4) Figure 1.

HD tigeciclyne: loading dose of $200 \mathrm{mg}$, followed by $100 \mathrm{mg}$ twice a day; SD tigecycline: loading dose of $100 \mathrm{mg}$, followed by $50 \mathrm{mg}$ twice a day. HD meropenem 2 gms three times per day. LD colistin: $5 \mathrm{mg} / \mathrm{kilo}$ with a maximum dose of $300 \mathrm{mg}$. Triple therapy is a combination of colistine, tigeciclyne, meropenem.

\begin{tabular}{|l|l|}
\hline Variable & Mean \pm SD*/ Total (\%) \\
\hline
\end{tabular}

Table 4: Treatment strategies applied to the patients including double and triple therapy, high doses and loading doses.

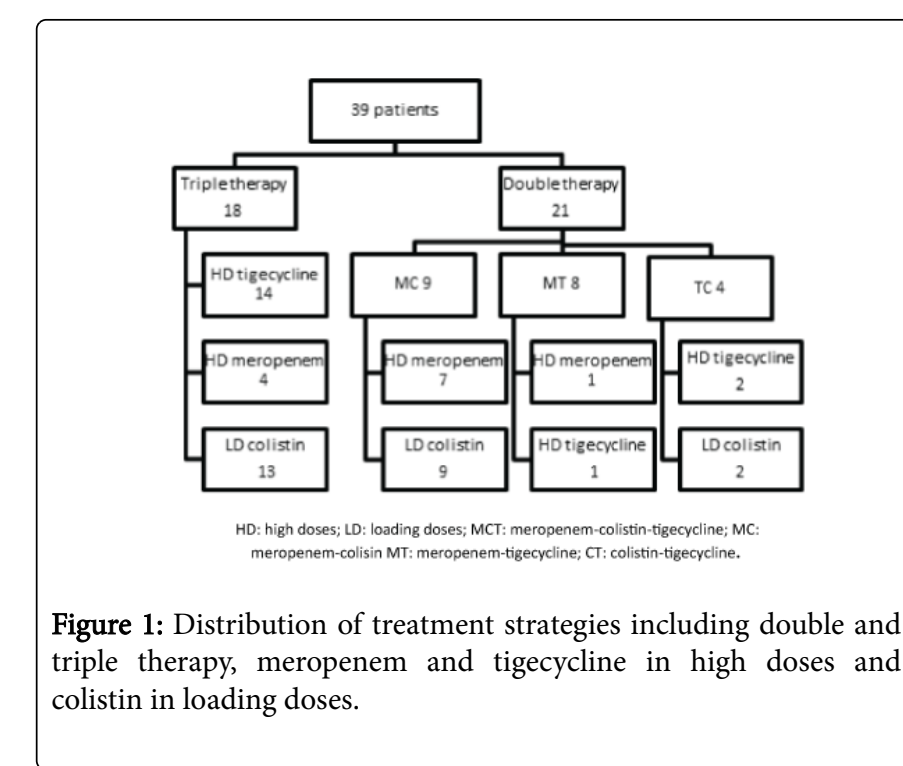

The sole adverse effect reported with the use of tigecycline was nausea in 6 patients (20\%), however any patient required suspension of the medication, only antiemetic therapy was required. Eight patients (25\%) receiving colistin required dose titration after 5 days due to the presence of AKI, of these 4 normalized renal function and 4 died. The overall mortality was $33.3 \%$ (13 patients), the mean value for the days of stay in the ICU was 12.8 days (SD \pm 16.2 ), and the total days of hospitalization were $41(\mathrm{SD} \pm 25.9)$. $77 \%$ of patients had a q-SOFA scale equal or over 2 points. Mortality with the triple therapy was of $25.3 \%$, mortality with double therapy was as follows: MC $40 \%$, MT $37.5 \%$, and TC $25 \%$. Mortality in patients receiving tigecycline at high doses was $33.3 \%$ (Table 5).

\begin{tabular}{|l|l|}
\hline Variable & Mean \pm SD/Total (\%) \\
\hline Death & $13(33.3)$ \\
\hline
\end{tabular}


Citation: Islas-Muñoz, Liudmila VA, Daniel AZ, Rafael VV, Eduardo LE, et al. (2017) Strategies of Treatment for Extensively Drug-Resistant Acinetobacter baumannii Infections: Single Centre Experience. J Infect Dis Med 2: 106. doi:10.4172/2576-1420.1000106

Page 4 of 6

\begin{tabular}{|l|l|}
\hline Death with MCT & $5(27.7)$ \\
\hline Death with MC & $4(44.4)$ \\
\hline Death with MT & $3(37.5)$ \\
\hline Death with CT & $1(25)$ \\
\hline Stay longer than 30 days with MCT & $14(77)$ \\
\hline Stay longer than 30 days with MC & $5(55)$ \\
\hline Stay longer than 30 days with MT & $2(25)$ \\
\hline Stay longer than 30 days with CT & $1(25)$ \\
\hline
\end{tabular}

Table 5: Clinical outcomes including death, invasive mechanical ventilation, admission to ICU and stay longer than 30 days.

Outcomes after 72 hours of admission reveals absence of fever in $66 \%$ of patients; absence of leukocytosis and withdrawal of vasopressors in $59 \%$ and $56.5 \%$ of patients respectively (Table 6).

Figure 2 compares these outcomes between the triple and double therapy, any statistically significant difference was found. $77 \%$ of patients had a q-SOFA scale equal or over 2 points.

\begin{tabular}{|l|l|}
\hline Variable & Mean \pm SD/ Total (\%) \\
\hline Abscense of fever & $26(66.6)$ \\
\hline Abscense of leukocytosis & $23(59)$ \\
\hline Thrombocytosis & $3(7.6)$ \\
\hline Thrombocytopenia & $7(17.9)$ \\
\hline Vasopressors withdrawal & $22(56.5)$ \\
\hline Acute kidney injury & $18(46)$ \\
\hline
\end{tabular}

Table 6: Clinical outcomes 72 hours after admission.

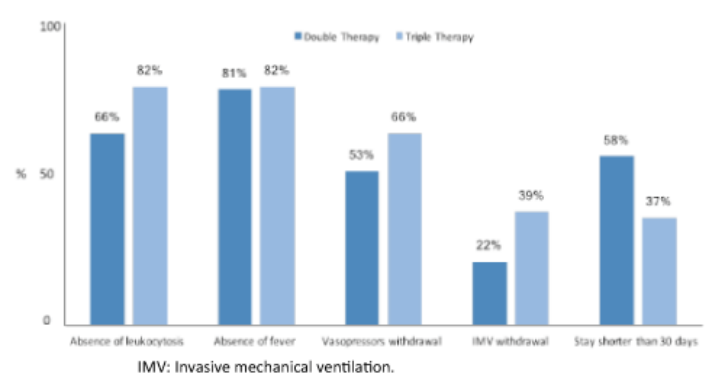

Figure 2: Comparative of clinical outcomes after 72 hours of admission double versus triple therapy.

When we compared the mortality rates between the different treatment strategy groups, we found that CT and MCT combinations had the lowest rates (25\% and $28 \%$ respectively) compared with MC and MT combination groups (Figure 3). Mortality with triple therapy (MCT) was $25 \%$ compared with overall and dual therapy (40\%) with no statistical significance $(\mathrm{p}=0.70$ ) (Figure 4 ). HAP caused $69 \%$ of deaths, followed by abdominal infections $15 \%$, SSTI and urosepsis $8 \%$ each one respectively (Figure 5).

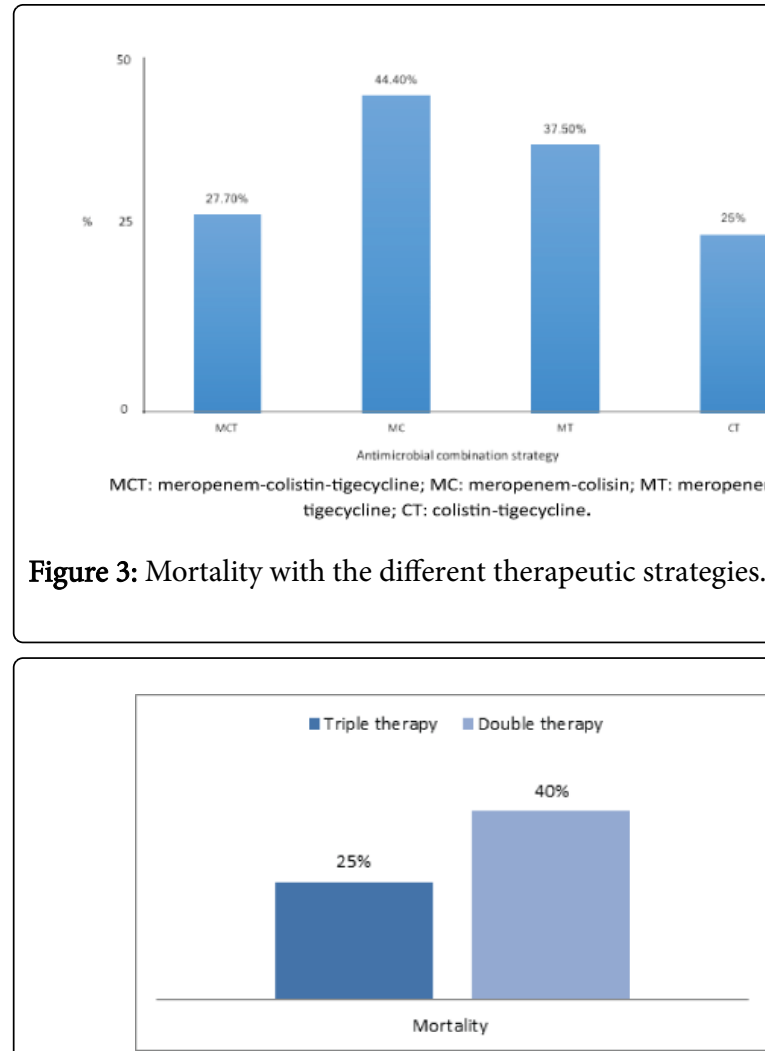

Figure 4: Mortality comparing triple vs double therapy.

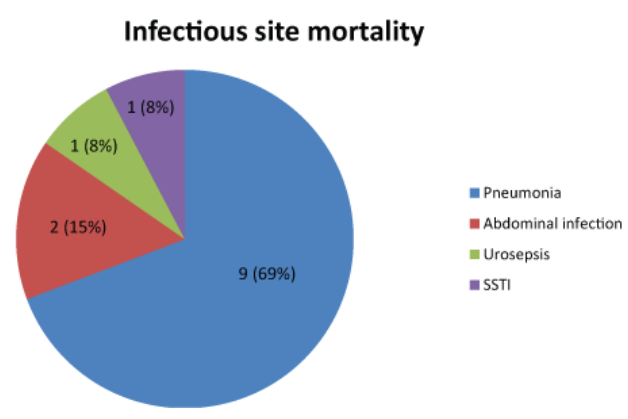

Figure 5: Mortality per infectious site. SSTI: Skin and soft tissue infections.

Comparing the stay at the ICU, HAP was $79 \%$ vs. $11 \%$ of patients with SSTI. Concerning the q-SOFA scale, 96\% of patients with pneumonia and $33 \%$ of patients with SSTI had a score equal or over 2 . Regarding antimicrobial agents administered to the HAP group, 50\% received the triple therapy, $25 \%$ received $\mathrm{MC}$, and $21 \%$ received MT. The combination of antimicrobial agents used in the group of SSTI was mainly MT in $44 \%$, followed by MC in $33 \%$ and $22 \%$ had triple therapy.

\section{Discussion}

Several in vitro studies have shown a clear advantage of using combined therapy to treat XDR A. baumannii. The microbiological 
explanation for this strategy is that the use of colistin increase permeability of the outer membrane, allowing penetration and increasing activity of the drug with which it is combined. Several combinations have been tested and the results of most of them show synergy and even the ability to prevent drug-resistant strains. In a systematic review and meta-analysis, Ni Wentao et al. analyzed 70 published studies and 31 conference proceedings for in vitro studies with strategies of combined therapy with polymyxins and 28 different antimicrobial agents used against $A$. baumannii. In addition to synergy, it was also observed that the combination with carbapenems or rifampicin was efficient to prevent the development of resistance to colistin, as well as a synergy of more than $50 \%$ for colistin-resistant strains [21].

In our study general mortality was lower than that reported in the literature. Due to the multiple comorbidities, severity of the disease and stay at ICU, it was difficult to determine the infection associated mortality per se. There was mild improvement shown in mortality for the triple therapy, although this result was not statistically significant. The mortality and clinical outcomes changed with the infectious site, HAP patients had a higher mortality and higher scores in the q-SOFA scale compared with SSTI patients.

It is difficult to determine the specific cause that resulted in lower mortality in our study because there was no access to certain relevant data on the medical records to assess in a more objective way the baseline clinical condition of patients, such as APACHE II and qSOFA. Due to the sample size, no statistically significant differences were seen for the different therapeutic strategies. However, a trend towards decreased mortality was observed in the triple therapy group compared to the other strategies.

When assessing the adverse effects associated to the administration of $\mathrm{HD}$ of tigecycline and $\mathrm{LD}$ of colistin, no serious alterations were observed that required discontinuing antimicrobial agents. Since a high percentage of the patients included in the study were under sedation with invasive mechanical ventilation, the presence of nausea with high doses of tigecycline was not a frequently reported adverse effect. AKI associated with the use of colistin did not exceed that reported in the literature with the use of this antimicrobial agent.

Our study did not shown increased mortality in the tigecycline group, which may be explained by the use of higher doses and by the combination with other antimicrobials. In the last five years at our center, we justified the use of combined therapy because susceptibility to colistin and tigeciclyne was unknown in the routine laboratory, and because the use of VITEK system for identifying $A$. baumannii resistance have error rate of $7.2 \%$ [22].

Despite in vitro studies of synergy combining two or more antimicrobials have shown promising results clinical trials have not been able to demonstrate improvement in clinical outcomes. There are two randomized clinical trials and one observational study that evaluated combinations of colistin with rifampicin or fosfomycin and all failed to prove difference in mortality [23]. However since 2017 CLSI (Clinical \& Laboratory Standards Institute) guidelines emphasize that colistin should generally be given at maximum recommended doses and used in combination with other agents [24].

In 2006, hetero-resistance was reported for the first time in $A$. baumannii, which is defined as the occurrence of resistance to colistin of a subpopulation from a susceptible strain $(\mathrm{MIC}<2 \mathrm{mcg} / \mathrm{l})$. Available reports provide rates ranging from $18 \%$ to $100 \%$ of hetero-resistance in strains [25]. Rodríguez et al. [26] showed that in vitro combinations of colistin with rifampicin have synergistic activity in hetero-resistant strains and prevents the development of resistant mutants to colistin.

Reasons that support the use of combined therapy at this moment are: microbiological synergy, and lack of an accurate test for detecting colistin resistance. With the results obtained at our Centre, the availability of automatized systems for susceptibility tests and knowledge about pharmacokinetics it is possible to propose an algorithm of treatment for rationalize and optimize the use of antimicrobials in agreement with the infectious site and MIC of the microorganism (Figure 6). This strategy let us adjust the treatment to the clinical and microbiological condition of each patient. Our strategies are directed to improve survival of patients, better clinical outcomes and prevention of the emergence of resistant $A$. baumannii strains.

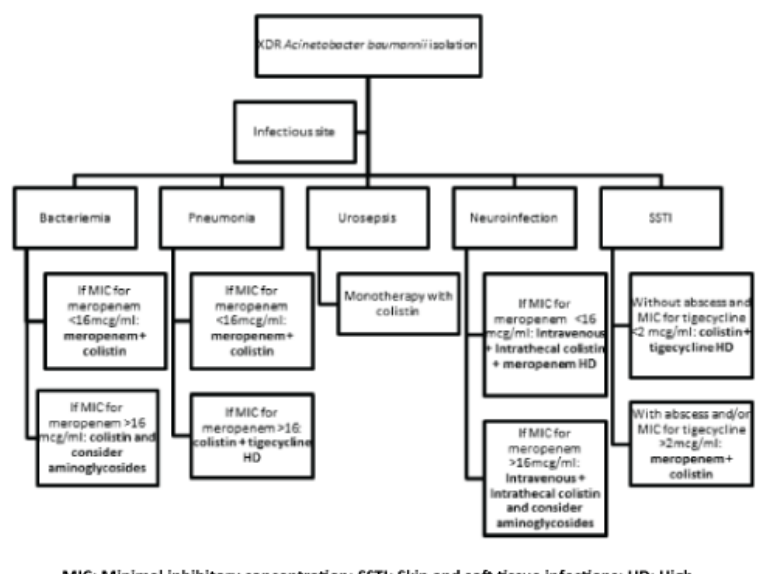

doses

Figure 6: Proposed algorithm for treatment of infections caused by XDR A. baumannii taking on account site of infection and MIC of antimicrobials.

\section{Conclusion}

XDR $A$. baumannii is a threatened microorganism that implies outbreaks at ICU and high rates of mortality in hospitalized patients. The combinations of antimicrobials are the cornerstone of treatment of A. baumannii.

We conclude that LD colistin, HD tigecycline and HD meropenem used in combined therapy when we don't know susceptibility was safe and the mortality was similar or lowest to the reported in the literature. In the case of colistin and tigecyline we recommend its use with double therapy taking into account the minimum inhibitory concentration and the site of infection. In the emergence of XDR microorganism is important to consider the availability of old antimicrobials that could contribute to the treatment of this infections besides the new betalactamics combined with betalactamse inhibitors drugs.

In case of presence of XDR microorganisms it is important not only focus on therapeutic protocols but also in taking preemptive actions for avoid it's dissemination. In the real world the management of resistant strains is becoming a frequent hospital issue, to ignore the susceptibility of the drugs that are being used confer a future risk of therapeutic failures or resistance. More studies must be done for a 
Citation: Islas-Muñoz, Liudmila VA, Daniel AZ, Rafael VV, Eduardo LE, et al. (2017) Strategies of Treatment for Extensively Drug-Resistant Acinetobacter baumannii Infections: Single Centre Experience. J Infect Dis Med 2: 106. doi:10.4172/2576-1420.1000106

Page 6 of 6

better understanding of in vivo combination of antimicrobials for the treatment of infections related to A. baumannii.

\section{References}

1. Allen DM, Hartman BJ (2005) Acinetobacter species. In: Mandell L, Bennett JE, Dolin R (eds.). Mandell, Douglas and Bennett's principles and practice of infectious disease (6th edn.). Elsevier Churchill Livingstone, Philadelphia. pp: 2632-2636.

2. Murray C, Hospenthal D (2005) Treatment of multidrug resistant Acinetobacter. Curr Opin Infect Dis 18: 502-506

3. Jain R, Danziger LH (2004) Multidrug-resistant Acinetobacter infections: an emerging challenge to clinicians. Ann Pharmacother 38: 1449-1459.

4. Garnacho J, Sole-Violan J, Sa-Borges M, Diaz E, Rello J (2003) Clinical impact of pneumonia caused by Acinetobacter baumannii in intubated patients: A matched cohort study. Crit Care Med 31: 2478-2482.

5. Blot S, Vandewoude K, Colardyn F (2003) Nosocomial bacteremia involving Acinetobacter baumannii in critically ill patients: A matched cohort study. Intensive Care 29: 471-475.

6. Falagas M, Kasiakou S, Rafailidis P, Zouglakis G, Morfou P (2006) Comparison of mortality of patients with Acinetobacter baumannii bacteraemia receiving appropriate and inappropriate empirical therapy. J Antimicrob Chemother 57: 1251-54.

7. Chopra I, Roberts M (2001) Tetracycline antibiotics: Mode of action, applications, molecular biology, and epidemiology of bacterial resistance. Microbiol Mol Biol Rev 65: 232-260.

8. Martínez JA (2016) Approach to directed therapy after knowledge of the isolate: Carbapenemase-producing Enterobacteriaceae, multidrugresistant Pseudomonas aeruginosa and carbapenem-resistant Acinetobacter baumannii. Rev Esp Quimioter 29: 31-34.

9. Ni W, Han Y, Liu J, Wei C, Zhao J, et al. (2016) Tigecycline treatment for carbapenem-resistant enterobacteriaceae infections: A systematic review and meta-analysis. Medicine (Baltimore) 95: 1-10.

10. Karageorgopoulos D, Kelesidis T, Kelesidis I, Falagas MD (2008) Tigecycline for the treatment of multidrug-resistant (including carbapenem-resistant) Acinetobacter infections: A review of the scientifici evidence. J Antimicrob Chemother 62: 45-55.

11. Schafer JJ, Goff DA, Stevenson KB, Mangino JE (2007) Early experience with tigecycline for ventilator-associated pneumonia and bacteremia caused by multidrug-resistant Acinetobacter baumannii. Pharmacotherapy 27: 980-987.

12. De Pascale G, Montini L, Pennisi M, Bernini V, Maviglia R, et al. (2014) High dose tigecycline in critically ill patients with severe infections due to multidrug-resistant bacteria. Critical Care 18: R90.

13. Gordon N, Wareham W (2009) A review of clinical and microbiological outcomes following treatment of infections involving multidrug-resistant Acinetobacter baumannii with tigecycline. J Antimicrob Chemother 63: 775-780.

14. Ye JJ, Lin HS, Yeh CF, Wu YM, Huang PY, et al. (2016) Tigecycline-based versus sulbactam-based treatment for pneumonia involving multidrug- resistant Acinetobacter calcoaceticus-Acinetobacter baumannii complex. BMC Infect Dis 16: 374.

15. Li J, Nation R, Turnidge J, Milne R, Coulthard K, et al. (2006) Colistin: The re-emerging antibiotic for multidrug-resistant gram-negative bacterial infections. Lancet Infect Dis 6: 589-601.

16. Falagas ME, Rizos M, Bliziotis IA, Rellos K, Kasiakou SK, et al. (2005) Toxicity after prolonged (more than four weeks) administration of intravenous colistin. BMC Infect Dis 5: 1 .

17. Li J, Yang X, Chen L, Duan X, Jiang Z (2017) In Vitro activity of various antibiotics in combination with tigecycline against Acinetobacter baumannii: A systematic review and meta-analysis. Microb Drug Resist.

18. Timurkaynak F, Can F, Azap OK, Demirbilek M, Arslan H, et al. (2006) In vitro activities of non-traditional antimicriobials alone or in combination against multidrug-resistant strains of Pseudomonas aeruginosa and Acinetobacter baumannii isolated from intensive care units. Int J Antimicrob Agents 27: 224-228.

19. Lehard JR, Thamlikitkul V, Silveira FP, Garonzik SM, Tao X, et al. (2017) Polymyxin-resistant, carbapenem-resistant Acinetobacter baumannii is eradicated by a triple combination of agents that lack individual activity. J Antimicrob Chemother 72: 1415-1420.

20. DeFrances CJ, Cullen KA, Kozak LJ (2007) National hospital discharge survey: 2005 annual summary with detailed diagnosis and procedure data. Vital Health Stat 165: 1-209.

21. Ni W, Shao X, Di X, Cui J, Wang R, et al. (2015) In vitro synergy of polymyxins with other antibiotics for Acinetobacter baumannii: A systematic review and meta-analysis. Int J Antimicrob Agents 45: 8-18.

22. Kulah C, Aktas E, Comert F, Ozlu N, Akyar I, et al. (2009) Detecting imipenem resistance in Acinetobacter baumannii by automated systems (BD Phoenix, Microscan WalkAway, Vitek 2); high error rates with Microscan WalkAway. BMC Infect Dis 9: 30.

23. Zusman O, Altunin S, Koppel F, Dishon BY, Gedik H, et al. (2017) Polymyxin monotherapy or in combination against carbapenem-resistant bacteria: systematic review and meta-analysis. J Antimicrob Chemother 72: 29-39.

24. No authors listed (2017) Performance standards for antimicrobial susceptibility testing (27th edn). Clinical and Laboratory Standards Institute, Wayne PA.

25. Cai Y, Chai D, Wang R, Liang B, Bai N (2012) Colistin resistance of Acinetobacter baumannii: clinical reports, mechanisms and antimicrobial strategies. J Antimicrob Chemother 67: 1607-1615.

26. Rodríguez $\mathrm{CH}$, De Ambrosio A, Bajuk M, Spinozzi M, Nastro M, et al. (2010) In vitro antimicrobials activity agents endemic Acinetobacter baumannii multiresistant clones. J Infect Dev Ctries 4: 164-167

27. Seymour C, Liu V, Iwashyna T, Brunkhorst F, Rea T, et al. (2016) Assessment of clinical criteria for sepsis, for the third international consensus definitions for sepsis and septic shock (sepsis-3). JAMA 315: 762-774. 